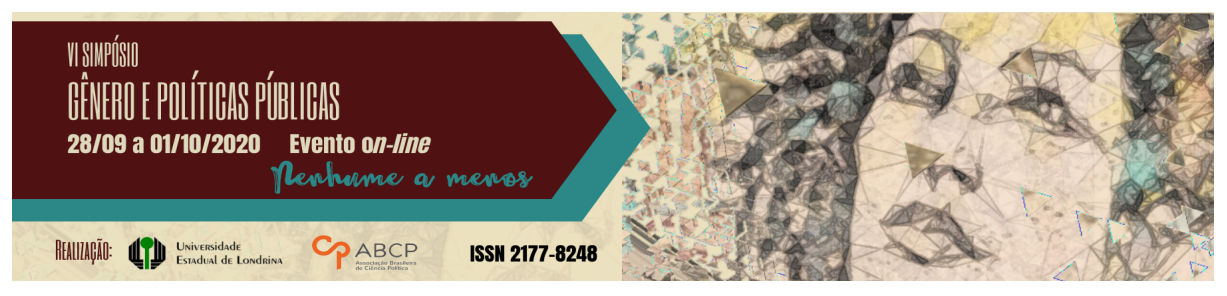

\title{
Trabalho de conclusão de curso mediando a iniciação científica por meio da educação sexual: um relato de experiência
}

\author{
Maria Lygia Alexandre Correiaㄹ; Bruna Larissa Ramalho Diniz²
}

\begin{abstract}
Resumo
O Trabalho de Conclusão de Curso representa um componente importante para a Iniciação Científica e constituição do graduando enquanto pesquisador. Apesar disso, várias são as dificuldades enfrentadas por indivíduos inexperientes quando se trata de iniciação à pesquisa. $\mathrm{O}$ objetivo do presente artigo é relatar as impressões e percepções construídas pela pesquisadora durante a realização de um TCC no campo da Educação Sexual, uma área em constante ataque na conjuntura político-social brasileira. Esses ataques criam um ambiente hostil para o desenvolvimento de ações e pesquisas relacionadas às temáticas de sexualidade e gênero, o que ficou bastante evidente na etapa da coleta de dados por meio de entrevistas semiestruturadas realizadas com professores da Educação Básica.
\end{abstract}

Palavras-chave: trabalho de conclusão de curso; educação para a sexualidade; pesquisa científica.

\footnotetext{
1 Universidade Estadual Júlio de Mesquita Filho (UNESP), Mestranda do Programa de Pós-Graduação em Educação para a Ciência UNESP/Bauru. Bióloga pela Universidade Estadual do Norte do Paraná (UENP), lygia.correia@unesp.br.

2 Universidade Estadual Júlio de Mesquita Filho (UNESP), Doutoranda do Programa de Pós-Graduação em Educação para a Ciência UNESP/Bauru. Bióloga pela Universidade Estadual de Maringá (UEM) e Mestra em Educação para a Ciência e a Matemática (PCM/UEM), bruna.diniz@unesp.br.
}

GT 08 - Gênero, educação e escola 


\title{
Under graduation paper mediating scientific iniciation through sex education: an experience report
}

\begin{abstract}
The final Undergraduation Paper represents an important component to the scientific iniciation and improvement of the undergraduating student as a research scientist. Neverthless, there are several challenges faced by the inexperienced university student when comes about scientific initiation. This paper focus on a experience and perception report of a final undergraduation work with Sex Education topics constructed by the researcher, an area under constant attack in the actual Brazilian political and social scenario. Those attacks create a hostile environment to the development of actions and research related to themes of sexuality and gender, wich is quite evidente in the stage of data collection through interwiews with teacher of Basic Education.
\end{abstract}

Keywords: undergraduation paper; education for sexuality; scientific research.

\section{Introdução}

O Trabalho de Conclusão de Curso (TCC) representa uma parte integrante na Iniciação Científica na graduação, podendo, muitas vezes, ser o primeiro contato do aluno com o campo da pesquisa científica. Assim, o TCC tem grande relevância para o processo de aprendizagem do graduando enquanto pesquisador, pois permite que este entre em contato com leituras, além de estimular o pensamento crítico e promover a resolução de problemas (SEVERINO, 2007, p. 202).

Embora seja um importante pilar para sua constituição enquanto universidade, a pesquisa, é, por muitas vezes, desvalorizada no meio acadêmico, o que torna o TCC um trabalho árduo e moroso. Em consequência, a inexperiência é um elemento a se considerar quando se trata de Iniciação Científica, e ao se deparar com o TCC, dúvidas manifestam-se a respeito de todo o processo que envolve a pesquisa científica, desde a escolha do tema a ser pesquisado, a coleta de dados e até a escrita do trabalho final. É necessário que o aluno deixe sua zona de conforto em busca de construir o próprio conhecimento científico (BONIN, 2006, p. 27). 
Dentre as dificuldades encontradas na elaboração do TCC, aponta-se indecisão quanto ao tema a ser pesquisado, falta de planejamento, hesitação quanto às etapas metodológicas que compõem uma pesquisa e processo de escrita acadêmica. Nesse cenário, o orientador tem um importante papel para o desafogamento de tais desinformações/desencontros/ignorâncias, direcionando o aprendiz para a supressão dessas incertezas metodológicas e epistemológicas (PRAÇA, 2006 p.73).

Para concretização de uma pesquisa científica, se faz necessário conhecer o assunto pesquisado, bem como, apreciar o tema do qual se pesquisa. O interesse no tema permite que aquele que o explora, busque informações com mais afinco a fim de responder às questões propostas de pesquisa, visto que elas passam a ter um sentido especial pois o pesquisador se importa pessoalmente com tais indagações. Assim, é possível se empolgar com o aprendizado que se manifesta durante o processo de planejamento e execução da pesquisa, facilitando a travessia por entre tribulações que venham surgir (PITTA; CASTRO, 2006, p. 243).

Quando se trata de pesquisas na área da Educação para a sexualidade, as dificuldades vão além dos obstáculos no campo metodológico, uma vez que a temática, muitas vezes, esbarra em questões morais e religiosas, bem como preconceitos e tabus já enraizados na sociedade (GONÇALVES; FALEIRO; MALAFAIA, 2013, p. 253). As adversidades recorrentes incluem a falta de tato do pesquisador ao abordar o assunto devido ao despreparo pedagógico, uma vez que essa temática nem sempre se faz presente nos cursos de graduação, bem como o receio ao preconceito de seus pares que poderia surgir devido a concepção errada do que é a Educação Sexual (BIANCON, 2005, p. 14).

Atualmente, o cenário tem se tornado cada vez mais desfavorável à pesquisas e abordagens sobre Sexualidades e Gênero no espaço escolar. Em tentativa ao controle moral da educação, surgem falácias que visam depreciar condutas que se propõem a levar 
conhecimento e prevenção a crianças e adolescentes A citar as chamadas "Fake News", que vincularam inverdades como "Kit Gay", "mamadeira de piroca", "ideologia de gênero" e o chamado "projeto escola sem partido" (CARVALHO; POLIZEL; 2018, p. 603).

Neste contexto nacional efervescente e com uma série de sinais e evidências de retrocessos nos debates educacionais e nas conquistas de direitos sociais, é de extrema importância que pesquisas relacionadas à Educação para a sexualidade continuem a serem realizadas.

Atual cenário político-social brasileiro: a "construção" do caos

A pesquisa referente ao Trabalho de Conclusão de Curso aqui relatado teve como objetivo levantar as concepções de professores e funcionários de uma escola pública estadual a respeito de temas ligados à Educação Sexual. Foi realizado no ano de 2019, em meio a um turbilhão de conservadorismo, retrocesso no campo da Educação Sexual e ataques às manifestações de liberdade sexual. Tal perspectiva foi concebida ao longo dos anos por diferentes eventos que tiveram seu ápice em 2019, com a posse do presidente eleito que é assumidamente oposição à projetos de Gênero e Sexualidade em escolas. A seguir, descreveremos a construção do caos, idealizado e edificado em meio à diferentes eventos e acontecimentos.

Lançado pelo Governo Federal em meados de 2004, o Programa Brasil sem Homofobia tinha por objetivo conscientizar e combater a violência e discriminação contra a comunidade LGBT+ (Lésbicas, Gays, Bissexuais, Transgêneros, Transexuais, Travestis). Na elaboração do Plano de Combate à Discriminação contra a comunidade LGBT+, constavam ações de apoio à projetos voltados à discussão da temática, capacitação de profissionais a fim de atuar na promoção de defesa aos Direitos Humanos e envolviam apoio de diversas organizações voltadas para o acolhimento e apoio de homossexuais (BRASIL, 2004, p. 11). 
Tais ações se mostram necessárias, visto que a escola é um dos locais que mais disseminam as normas de gênero e reproduz a heteronormatividade, se configurando como um ambiente hostil para crianças e adolescentes que fogem à regra de performatividade de feminilidades e masculinidades (BENTO, 2011, p. 555). Assim, o Programa Brasil sem Homofobia se voltava para a produção de materiais que dialogassem com as diversidades, a fim de lidar com as pluralidades em ambiente escolar. Tais materiais incluíam folders explicativos, cartilhas com histórias e representatividade, bem como materiais de apoio com temática relacionada a sexualidade voltados para professores.

Durante Seminário do "Escola Sem Homofobia" na Câmara de Deputados do Congresso Nacional em 2010, os materiais foram recebidos com críticas por parte da comunidade conservadora e dos fundamentalistas religiosos. Recortes das cartilhas foram retirados de contexto e expostos, o que gerou uma polêmica que depreciava os princípios do programa como um todo, sendo cunhado como "Kit Gay". As alegações eram de que o "Kit Gay" seriam impostos a crianças em tenra idade, e que poderiam influenciar a sexualidade, uma afirmativa equívoca e homofóbica (DE OLIVEIRA JR; MAIO, 2017 p. 139).

Tal controvérsia despontou o Movimento Escola Sem Partido, que ganhou força com as declarações lapsas sobre o Programa de Valorização à Diversidade. Integrantes do movimento se posicionavam contrários a chamada "Ideologia de Gênero", que segundo eles, é a imposição de uma pressão, advindos da discussão sobre gênero e sexualidade em salas de aula, indo contra os valores familiares de moral e bons costumes (JUNQUEIRA, 2019, p. 2). Para Carvalho, Polizel e Maio (2016, p. 202) o projeto “Escola Sem Partido é uma formação discursiva com enunciados difusos que já estão produzindo efeitos e conformando sujeitos, professores e alunos como objetos e alvos de suas falas".

A campanha do Ministério da Mulher, da Família e dos Direitos Humanos em conjunto com o Ministério de Saúde, intitulada de "Tudo 
tem seu tempo: adolescência primeiro, gravidez depois" reflete esse retrocesso e traduz a noção que parte da população tem a respeito da informação para crianças e adolescentes quando se trata de prevenção. Segundo adotado na elaboração a Política Nacional de Prevenção ao Risco da Atividade Sexual Precoce em 2020, optou-se pela disseminação da ideia de adiamento da iniciação sexual em adolescentes, pautado em iniciativas religiosas, de forma a evitar a gravidez na adolescência. Embora a expressão "abstinência sexual" não tenha sido exteriorizada, há um apelo pela protelação do início de atividades sexuais na adolescência (CABRAL; BRANDÃO, 2020, p. 1). O Conselho Regional de Saúde chegou a recomendar o cancelamento da Campanha de Abstinência Sexual, visto que seria uma tentativa falha de controle de corpos (CONSELHO, 2020, p. 1).

Todos esses episódios foram se construindo ao longo dos anos, legitimando a desinformação e o preconceito e gerando falácias que hoje são difundidas amplamente em território nacional por diferentes líderes de partidos e figuras religiosas. Tais discursos enviesados culminaram na desvalorização do diálogo sobre gênero e sexualidades, e afeta o importante papel da Educação Sexual nas instituições escolares.

$\mathrm{O}$ advento dos conservadores extremistas gerou, portanto, um retrocesso nas ações e debates educacionais no campo da Educação para a sexualidade, envolvendo em tabu e discursos de ódio temas que antes estavam caminhando para a desconstrução. É consequência disso, também, a manutenção de preconceitos na sociedade e a crescente dificuldade em abordar tais assuntos na escola, o que ficou evidente durante a coleta de dados para o TCC que foi desenvolvido no campo da Educação para a sexualidade.

\section{Caminhos metodológicos}

O objetivo do presente artigo é relatar as percepções e impressões sobre a investigação da Educação Sexual durante o período supracitado, envolto em brumas, enredado em caos e obscurantismo, 
através do Trabalho de Conclusão de Curso. Nesta seção, discorreremos sobre quando, onde, e como se deu esta experiência.

A pesquisa de TCC teve início no mês de março de 2019, com a delimitação do tema e delineamento do projeto de pesquisa, embora as leituras sobre o tópico em questão datam do início de 2018. A ânsia de fazer deste tema um objeto de estudo no TCC, foi uma maneira de exprimir o descontentamento com tamanho ataque por parte da comunidade política conservadora, que se tornou mais frequentes após início do mandato do então presidente. Tais ataques se materializaram também na comunidade escolar, através de discursos de professores e funcionários.

Para a coleta de dados foram utilizadas entrevistas semiestruturadas. Optou-se pela construção de um questionário de base para realização das entrevistas, de maneira a nortear a investigação. Leituras prévias foram necessárias a fim de aprimorar a articulação durante a intervenção junto aos participantes da pesquisa. As entrevistas ocorreram nas dependências do colégio, a fim de que os entrevistados estivessem à vontade e em um ambiente familiar, seu local de trabalho, com representantes da comunidade escolar, professores, gestores e zeladores.

A instituição na qual realizou-se as entrevistas localiza-se em uma área central de uma cidade no interior do estado do Paraná. O colégio em questão foi escolhido após observação pela pesquisadora de diversas falas da equipe pedagógica e administrativa relacionadas a gêneros e sexualidades em visitas anteriores não relacionadas com o tema. Tornando assim, um local propício para a investigação mais profunda de tais concepções demonstradas no recôndito de conversas despretensiosas.

Para execução da pesquisa de TCC, foi necessário cadastro do projeto na Plataforma Brasil, base nacional e unificada de registros de pesquisas envolvendo seres humanos, e aval do Comitê de Ética em Pesquisa com Seres Humanos (CEP) e da Comissão Nacional de Ética 
em Pesquisa (CONEP) que tem função de revisar se os protocolos de pesquisa estão de acordo com as práticas éticas, e assinatura de Termo de Consentimento Livre e Esclarecido (TCLE). Os sujeitos são entidades socioculturais e seus discursos podem ser pensados de maneira histórica, a pesquisa aqui mencionada, se enquadra, portanto, no caráter social das Ciências Humanas e Sociais (MAINARDES, 2017, p. 161).

Para a análise de dados, utilizou de Análise Textual Discursiva, que é "uma abordagem de análise de dados que transita entre duas formas consagradas de análise na pesquisa qualitativa que são a análise de conteúdo e a análise de discurso" (MORAES; GALLIAZI, p 117, 2006).

Desde a concepção da ideia, delineamento do projeto de pesquisa, execução da pesquisa, análise e descrição de resultados e divulgação das conclusões, foram cerca de um ano.

Percepções da pesquisadora

Desde a submissão ao CEP/Conep, até a deliberação do parecer favorável pela aprovação do projeto de pesquisa, foram 4 meses de tramitação, entre abril e agosto. A demora na emissão dos pareceres pode ser justificada pela grande quantidade de pedidos, que ultrapassam a capacidade de acompanhamento devido ao número reduzido de funcionários e das reuniões (BARBOSA et al, 2011, p.532). Tal delonga estagnou o período de coleta de dados e atrasou a pesquisa como um todo.

O uso de entrevista semiestruturada se faz oportuna pois existe a possibilidade de improvisar e acrescentar perguntas pertinentes ao assunto, viabiliza a aproximação do sujeito de pesquisa de maneira a deixá-lo mais confortável, promovendo uma obtenção de respostas mais satisfatórias (FLICK, 2009, p. 147). As perguntas versavam sobre situações envolvendo temáticas da sexualidade vivenciadas em ambiente escolar, sobre a importância de abordagem de Educação 
Sexual em ambiente escolar, em qual idade essas abordagens deveriam ocorrer e de que forma. Uma das perguntas era "Você considera que questões como diversidade sexual, diversidade de gênero, temáticas LGBT, devam ser tratadas no ambiente escolar? Como você lida com essas questões no dia-a-dia?".

Laperriére (2008, p.415) afirma que, uma pesquisa que implica interação entre observador e observado, a observação muda, visto que o observado sabe que está sendo observado, e pode, portanto, através da consciência de teste, ter mudanças de percepção e atitudes diante do observador. Apesar das vantagens, as entrevistas se mostraram difíceis de serem executadas devido a timidez dos participantes da pesquisa em dialogar sobre assuntos que permeiam as sexualidades, dando a impressão em vários momentos de que, por receio de julgamentos, omitiam informações e concepções que poderiam se caracterizar como pertinentes para a composição dos resultados da análise.

Figueiró, no livro "Educação Sexual, múltiplos temas, compromisso comum" (FIGUEIRÓ, 2009, p.40), reflete sobre essa dificuldade de falar sobre sexualidade e indaga: "Será pelo receio de que, ao assim fazer, também seriam desvelados os nossos valores, comportamentos, interesses e frustrações sexuais?".

Além das dificuldades relacionadas às entrevistas, como a pouca abertura dos entrevistados para dialogar temas das sexualidades, e o presente desconforto quando interpelados quanto às suas concepções, houve certa relutância de auto avaliar a presença ou ausência das práticas docentes relacionadas à Educação Sexual. Ainda de acordo com Figueiró:

Todos somos frutos de uma sociedade repressora em relação à sexualidade, na qual ainda perduram associações do sexo com ideias de pecado, de feio e de proibido, ou, por outro lado, com ideias de promiscuidade e de imoralidade. Neste contexto de formação cultural, acabamos carregando conosco uma gama de tabus, preconceitos e sentimentos, muitas vezes, negativos, em relação ao sexo, o que 
acentua nossa dificuldade em falar abertamente sobre ele (FIGUEIRÓ, 2009, p.142, grifo nosso).

Apreensiva, em diversos momentos ao longo da pesquisa fui acometida por um sentimento de impotência, diante de tantos ataques, mentiras e fabulações inventadas para enfraquecer um movimento que busca informar crianças, jovens e adolescentes sobre temas relacionados à sexualidade, para que possam viver a sexualidade de maneira crítica e emancipada, capazes de reconhecer abusos e riscos. Esses ataques criam um ambiente hostil para o desenvolvimento de ações e pesquisas relacionadas às temáticas de sexualidade e gênero.

Outro obstáculo que vale a pena mencionar, enquanto pesquisadora, foi o receio de ser mal interpretada. Por se tratar de um tema deveras delicado, dada a atual conjuntura político-social, foi necessário cautela desde a formulação dos questionários, até a análise de resultados. Resultados esses que evidenciaram o ambiente escolar como hostil para práticas e abordagens relacionados à temas da Educação Sexual.

O sentimento que perdurou durante todo o percurso de planejamento, execução da pesquisa e discussão de resultados, era de constante necessidade de afirmar a importância da investigação no campo da Educação para a sexualidade, o que tornou o processo da pesquisa bastante exaustivo.

A sensação era a de que não se estava permitido errar. Quando a iniciação científica se faz em outros campos, durante o percurso de aprendizagem é tolerado errar. Mas, quando se está trilhando os primeiros caminhos em direção à pesquisa em Educação Sexual, Sexualidades e Gêneros, a sensação é de que não se pode errar, pois apenas um erro pode colocar em cheque e deslegitimar toda a discussão em si, e da pesquisa em questão, não somente do pesquisador inexperiente.

\section{Considerações finais}


O Trabalho de Conclusão de Curso se mostrou como uma ferramenta satisfatória para a Iniciação Científica, embora a escolha de um tema cercado de tabus e preconceitos como a Educação para a sexualidade tenha gerado obstáculos para a conclusão da pesquisa. Todavia, todas as experiências e reflexões feitas ao longo desta jornada científica puderam contribuir de forma positiva para minha formação enquanto pesquisadora. $\mathrm{O}$ apoio e indicações de textos adequados para cada adversidade foi imprescindível para a conclusão desta tarefa árdua, mas prazerosa, e fez total diferença na construção do conhecimento.

Apesar das dificuldades, pesquisas no campo da Educação Sexual são de grande importância e devem permear os espaços educativos, além de constituírem-se como sinônimos de lutas e resistência, principalmente devido ao contexto político-social caótico que estamos vivendo.

Assim, é preciso refletir e discutir sobre as questões relacionadas à Educação para a sexualidade sem a pretensão de esgotá-las, ressaltando as possibilidades, as dificuldades, os conflitos, os avanços, os ganhos, os desafios, os propósitos e os despropósitos. Não se almeja chegar a conclusões, a respostas com tom de verdade ou definitivas; provisórias talvez! Importa, sobretudo, refletir, palpitar, questionar, problematizar, discutir, pensar sobre esses e outros assuntos, bem como tencionar discursos e provocar inquietações na discussão da interface entre sexualidade, gênero e educação (XAVIER FILHA, 2009, p.100).

\section{Referências}

BARBOSA, Adriana Silva et al. A Resolução 196/96 e o sistema brasileiro de revisão ética de pesquisas envolvendo seres humanos. Revista Bioética, v. 19, n. 2, p. 523-542, 2011.

BENTO, Berenice. Na escola se aprende que a diferença faz a diferença. Revista Estudos Feministas, Florianópolis, v. 19, n. 2, p. 549-559, 2011. 
BIANCON, Mateus Luiz. A educação sexual na escola e as tendências da prática pedagógica dos professores. 2005. Dissertação (Mestrado em Ensino de Ciências e Educação Matemática) - Universidade Estadual de Londrina, Londrina, 2005.

BONIN, Jiani Adriana. Nos bastidores da pesquisa: a instância metodológica experienciada nos fazeres e nas processualidades de construção de um projeto. In: MALDONADO, Efendy et al. Metodologias de pesquisa em comunicação. Porto Alegre: Sulina, 2006. p. 21-40.

BRASIL. Conselho Nacional de Combate à Discriminação. Brasil Sem Homofobia: Programa de combate à violência e à discriminação contra GLTB e promoção da cidadania homossexual. Brasília: Ministério da Saúde, 2004 Disponível em: http://sisnov.campinas.sp.gov.br/biblioteca/gerais/brasil_sem_ho mofobia.pdf. Acesso em: 30 ago. 2020.

CABRAL, Cristiane da Silva; BRANDÃO, Elaine Reis. Gravidez na adolescência, iniciação sexual e gênero: perspectivas em disputa. Cadernos de Saúde Pública, v. 36, p. e00029420, 2020.

CONSELHO, Nacional de Saúde. Recomendação no 004, de 24 de janeiro de 2020. Recomenda o cancelamento da Campanha de Abstinência Sexual, promovida pelo Ministério da Mulher, da Família e dos Direitos Humanos em conjunto com o Ministério da Saúde. Disponível em: http:// conselho.saude.gov.br/recomendacoes/2020/Reco004.pdf. Acesso em: 30 ago. 2020.

DE CARVALHO, Fabiana Aparecida; POLIZEL, Alexandre Luiz. O Escola Sem Partido e o discurso sobre uma suposta "Ideologia de Gênero". Revista Inter Ação, v. 43, n. 2, p. 600-614, 2018.

DE CARVALHO, Fabiana Aparecida; POLIZEL, Alexandre Luiz; MAIO, Eliane Rose. Uma escola sem partido: discursividade, currículos e movimentos sociais. Semina: Ciências sociais e humanas, v. 37, n. 2, p. 193-210, 2016.

DE OLIVEIRA JÚNIOR, Isaias Batista; MAIO, Eliane Rose. “Não vai ser permitido a nenhum órgão do governo fazer propaganda de opções sexuais": O discurso inaugural no "desagendamento" do kit gay do MEC. Revista e-Curriculum, v. 15, n. 1, p. 125-152, 2017. 
FIGUEIRÓ, Mary Neide Damico. Educação sexual: múltiplos temas, compromissos comuns. Londrina: EdUEL, 2009.

FLICK, Uwe. Introdução à pesquisa qualitativa. 3. ed. Porto Alegre: Editora Artmed, 2009.

GONÇALVES, Randys Caldeira; FALEIRO, José Henrique; MALAFAIA, Guilherme. Educação sexual no contexto familiar e escolar: impasses e desafios. Holos, v. 5, p. 251-263, 2013.

JUNQUEIRA, Rogério Diniz. "Ideologia de gênero": uma ofensiva reacionária transnacional. Revista Tempo e Presença, n. 32, 2019.

MAINARDES, Jefferson. A ética na pesquisa em educação: panorama e desafios pós-Resolução CNS n ${ }^{\circ} 510 / 2016$. Pontifícia Universidade Católica do Rio Grande do Sul Porto Alegre, Brasil. Educação, v. 40, n. 2, p. 160-173, maio/ago. 2017,

MORAES, Roque; GALIAZZI, Maria do Carmo. Análise textual discursiva: processo reconstrutivo de múltiplas faces. Ciência $\mathcal{E}$ Educação (Bauru), v. 12, n. 1, p. 117-128, 2006.

LAPERRIÉRE, A. Os critérios de cientificidade dos métodos qualitativos. In: POUPART, J. (Org.). A pesquisa qualitativa: enfoques epistemológicos e metodológicos. Rio de Janeiro: Vozes. 2008. p. 410435.

PITTA, Guilherme Benjamin Brandão; CASTRO, Aldemar Araújo. A pesquisa científica. Jornal Vascular Brasileiro, v. 5, n. 4, p. 243-244, 2006.

PRAÇA, Fabíola Silva Garcia. Metodologia da pesquisa científica: organização estrutural e os desafios para redigir o trabalho de conclusão. Revista Eletrônica Diálogos Acadêmicos, v. 8, n. 1, p. 72-87, 2015.

SEVERINO, A. J. Metodologia do trabalho científico. 23. ed. São Paulo: Cortez, 2007.

XAVIER FILHA, Constantina. Educação para a Sexualidade: carregar água na peneira? In: RIBEIRO, Paula Regina Costa et al. (Org.). Corpo, gênero e sexualidade: composições e desafios para a formação docente. Rio Grande: Editora da FURG, 2009. p. 85-103. 